\title{
Role of In-Flight Temperature and Velocity of Powder Particles on Plasma Sprayed Hydroxyapatite Coating Characteristics
}

\author{
Jan Cizek $^{\mathrm{a}, *}$, Khiam Aik Khor ${ }^{\mathrm{b}}$ \\ ${ }^{a}$ Institute of Materials Science and Engineering \\ Faculty of Mechanical Engineering \\ Brno University of Technology, Czech Republic \\ ${ }^{b}$ School of Mechanical and Aerospace Engineering \\ Nanyang Technological University, Singapore
}

(C) 2012. This manuscript version is made available under the CC-BY-NC-ND 4.0 license

(http://creativecommons.org/licenses/by-nc-nd/4.0/)

doi:10.1016/j.surfcoat.2011.09.058

Final version available from

http://www.sciencedirect.com/science/article/pii/S0257897211009455

\begin{abstract}
This paper presents a systematic research on the process of thermal spraying of HA encompassing all stages of layer deposition: powder production \& characterization (optimized production led to spherical $39.90 \pm 10.61 \mu \mathrm{m}$ powder with $0.0 \%$ content of tri-calcium phosphate [TCP] or tetra-calcium phosphate [TTCP] phases), plasma jet properties influence on the in-flight powder properties (major influence of spray distance factor), the influence of the in-flight temperature and velocity of hydroxyapatite powder particles (ranges of $2294 \mathrm{~K}-2708 \mathrm{~K}$ and $152 \mathrm{~m} \cdot \mathrm{s}^{-1}-291 \mathrm{~m} \cdot \mathrm{s}^{-1}$ ) on the final characteristics of the deposited coatings. Six combinations of the system parameters leading the low-medium-high in-flight properties were selected and the respective coatings were investigated, with some data in contradiction to previously published results. It was found that the temperature of the particles plays a critical role for the development of detrimental $\mathrm{CaO}$ (content increase of up to 14.6\%) and metastable TTCP (up to $49.5 \%$ ) phases in the coatings. Particles in-flight velocity was found to influence the open porosity of the coatings $(8.8 \%-27.9 \%)$ and have an impact on the micro-hardness and moduli of the coatings (relative differences of up to $2.8 \times$ ). Joint incidence of both in-flight properties was found to significantly influence the microstructure of the coatings and its respective surface roughness levels $\left(R_{a}=7.4-19.4 \mu \mathrm{m}\right)$. The morphology of impinging splats was found to be influenced by both the in-flight velocity (dominant factor) and temperature (secondary factor) of the HA particles.
\end{abstract}

Keywords: plasma spray, in-flight properties, coating characterization, hydroxyapatite

\section{Introduction}

A traditionally used calcium phosphate ceramics, hydroxyapatite has been well proven during the intensive research of its bioactive properties [1]. Generally indicated as $\mathrm{Ca}_{10}\left(\mathrm{PO}_{4}\right)_{6}(\mathrm{OH})_{2}$, crystalline and amorphous HA forms a major component of mammal bones [2] and is therefore a sought-for compound for e.g. dental and orthopaedic applications. However, mechanical properties of HA do not suffice in load-bearing applications. Deposition of HA layers onto metal components (e.g. hip joint replacements) is therefore carried out [3].

Bioactive HA coatings on metallic implants have been reported to [4]:

\footnotetext{
* Corresponding author

Email address: cizek@fme.vutbr.cz (Jan Cizek)
} 
- promote earlier stabilization of the implant in the surrounding bone, supporting the bone in-growth and improving the implant-bone bond strength

- decrease the release of metallic ions from the implant, reducing the possibility of intoxication in vascular system and subsequent health hazards

- shield the surface of the prosthesis substrate from environmental attacks, facilitating long-term function performance and lowering the risk of substrate failure in load bearing applications

- extend the functional life of an implant as compared to cemented implants

Numerous issues regarding the deposition of HA layers onto metallic substrate materials have arisen (e.g. adhesion of the layers and prospective delamination, coatings fractures, changes in phase composition due to surface treatment technology, selective evaporation of components, thermal shocks to substrate materials, etc.). Many of the issues were addressed and efforts of the research studies focused on various aspects of the process.

Procedure of pure bio-grade HA powder preparation has been published in e.g. [5] and optimization of its properties (calcination at temperatures 1100-1300 K [6], morphology control by spraying into water/nitrogen, amorphous content determination [7]) were described. The respective phenomena of HA powder characteristics and properties changes during the spray procedure have been investigated with respect to the feeding of the powder (internal vs. external feeding, HA suspension feeding [8]) and surrounding controlled atmosphere [9].

The spray procedure has also been assessed by numerical simulations. The various studies involved computing using the plasma jet enthalpy, particle morphologies and average size, surrounding atmosphere, momentum transfers due to various working gases and final particle trajectories within the plume and impact upon substrate (e.g. [10]). Related to the theoretical studies, a study by Dyshlovenko et al. [11] focused on the influence of four key spray parameters of the system onto the characteristics of HA powder and coatings sprayed onto substrates and into water using two different spray distances.

The main focus of the studies have been set to the physical, mechanical and chemical properties of the deposited HA coatings [12], their post-spray treatment (e.g. laser annealing) and biological studies of the in-vitro (usually SBF solutions) and in-vivo responses of the HA-coated specimens [13]. With respect to the biological role of HA, purity and crystallinity of the layers are of utmost importance. Synthetically produced HA usually retains higher crystallinity ratio than HA in biological tissues [14]. The ratio is determined by the production process and prospective heat treatment (mainly annealing temperature and time). High levels of crystallinity of synthetic HA are beneficial for long-term survivability and proper functional life of implant tin service while high resorbability of the amorphous phase and a presence of metastable phases are useful for accelerated implant fixation and promotion of faster bone remodeling [15].

Among the industry methods, plasma spray technology has been widely used owing to its versatility and the wide range of applicable materials. Using this method, the deposition of function performing, protective or biocompatible coatings is efficient, the process retains high deposition rates and the target coating thickness could be easily controlled [16].

The plasma spray process is basically a deposition of molten or semi-molten material onto prepared substrates to form a protective or function-performing layer. In the process, three major phases could be distinguished: a) the plasma jet generation, b) interaction of the powder particles with the jet during material feeding phase and c) the coating build-up on the prepared substrate. The plasma generation process and the plasma jet properties is influenced by a number of factors. These could be divided into two groups: partially uncontrollable, often environment-bound and the factors selected and altered in the system. The latter parameters influence e.g. the temperature space distribution within the jet or the flow of the working gases (thus the momentum to be transferred to the particles). The interaction of the particles during the feeding phase is driven by e.g. the particle size distribution, the momentum of particles when entering the jet (determined by the carrier gas flow) or the particle dwelling time within the hot plasma region [16]. The final coating build-up is driven by the chemical and physical properties of the substrate (for the $1^{\text {st }}$ layer) and the thermodynamic and chemical properties of the deposited materials (successive layers). 
Encompassing all the three major phases (a-c), the aim of this study was to investigate the influence of the two most important in-flight factors (temperature, velocity) of the hydroxyapatite powder ("HA") on selected properties of the final coatings. Six parameters of the plasma spray system were selected to represent the variability in the phase of plasma jet generation [6]. Eighteen combinations of these parameters were investigated according to Taguchi experimental design and the respective in-flight properties were recorded. Subsequently, six combinations of the spray system parameters leading to low/medium/high in-flight properties (temperature, velocity) of HA particles were selected for coatings deposition. Characterization of the deposited layers was then carried out considering the powder in-flight properties. With respect to the prospective biomedical application of the HA coatings, microstructure, phase composition and porosity of the coatings were then studied as well as its surface roughness, elastic moduli and microhardness. To aid in our understanding of the deposition process (namely the $1^{\text {st }}$ layer phenomenon), single splat collection experiment was carried out.

\section{Experimental Setup}

\subsection{Powder Feedstock}

In this study, wet chemical synthesis precipitation reaction (1) was used to prepare the HA powder. To facilitate the precipitation, the phosphoric acid was added in a drop-wise manner under controlled temperature of $320 \mathrm{~K}$ and the process was terminated when $\mathrm{pH}$ dropped to 8.9 [17].

$$
10 \mathrm{Ca}(\mathrm{OH})_{2}+6 \mathrm{H}_{3}\left(\mathrm{PO}_{4}\right) \longrightarrow \mathrm{Ca}_{10}\left(\mathrm{PO}_{4}\right)_{6}(\mathrm{OH})_{2}+18 \mathrm{H}_{2} \mathrm{O}
$$

The produced saturated HA-water slurry could contain metastable phases, such as TCP or TTCP. However, these phases are susceptible to continuous dissolution in a non-saturated aqueous solution as compared to more stable HA phase and precipitation of additional HA is likely to occur during this process [18]. Therefore, to furthermore aid in retaining non-contaminated HA, the slurry was left to settle for 48 hours, leading to separation of water and the HA precipitate. The deionized water was then replaced and mixed into the slurry again. This process was repeated five times.

The slurry was then spray dried using rotary atomizer nozzle under previously optimized parameters (10 Hz atomizer revolution frequency, $510 \mathrm{~K}$ chamber temperature, $\sim 40 \mathrm{~g} \cdot \mathrm{min}^{-1}$ slurry feeding). The powder produced under these conditions demonstrated the highest yield and average particle sizes suitable for plasma spraying while retaining a relatively low intrinsic porosity. As the influence of the powder particle size on the properties was not investigated in this study, it was necessary to minimize its potential effect. Proper sieving resulted in obtaining a narrow distribution of the particle diameters, measured as $39.90 \pm 10.61 \mu \mathrm{m}$ by liquid suspension laser analysis.

The powder was calcined at $1220 \mathrm{~K}$ for 120 mins to further aid in the purification process and to increase the coalescence of the nanometric size crystallites within the particles [5], [19]. SEM investigation of the HA powder (Fig. 1) revealed a spherical nature of particles suitable for plasma deposition. Powder cross-section analysis indicated a porous structure of the powder. The intrinsic porosity was specified as $8.0 \%$ by helium pycnometric method.

The heat-treatment of the powder resulted in increased crystallinity of the HA powder. This was confirmed by narrowing of the HA peaks and their relative height increase in the measured XRD pattern (Fig. 2). For comparison purposes, a theoretical calculated prediction of pure HA pattern is included (HA ICSD \#26205 standardized pattern was used in ATOMS software to calculate the hkl planes, $d$ spacing values, symmetry and space group. The calculated information was then used in commercial PowderCell software for the spectra calculation). Rietveld analysis [20] was then used for determination of the powder phase content (Table 1). It could be seen that the HA powder contained a $5 \%$ amount of calcium carbonate phase and no traces of TCP and TTCP phases were detected. The detected $\mathrm{CaCO}_{3}$ could

have originated in the material by a reaction of the original $\mathrm{Ca}(\mathrm{OH})_{2}$ with atmospheric carbon dioxide (2) during the long-running synthesis. Water, the only by-product of this reaction, was then removed during the subsequent spray drying process, which $\mathrm{CaCO}_{3}$ undertook together with the introduced $\mathrm{HA}$ powder.

$$
\mathrm{Ca}(\mathrm{OH})_{2}+\mathrm{CO}_{2} \longrightarrow \mathrm{CaCO}_{3}+\mathrm{H}_{2} \mathrm{O}
$$




\subsection{Plasma System}

In this study, Praxair plasma system (Praxair Inc., Danbury, USA) equipped with Praxair SG-100 gun was used. Purified argon was used as a main arc forming gas and carrier gas and helium was used as an auxiliary gas.

The variability of the system was represented by six selected factors: net power, flow of the main and auxiliary gases, revolutions of the powder feeder wheel, flow of the carrier gas and spray distance, i.e. the distance between the gun and the target (Table 2). In the system, the six factors represent the most robust parameters influencing the properties of the plasma jet and the subsequent interaction of the powder during its penetration into the plume.

The net power $[\mathrm{kW}]$ function regulates the closed loop control function of the plasma energy by changing the DC power input instantly. It reacts to the changing physical conditions, automatically adjusting the spray parameters to maintain a constant powder heating region. Generally, increase in net power gives rise to jets of higher temperature and velocity. The relative increase of the two respective properties is important: higher plasma jet temperatures transfer more heat to the powder particles, however, the higher velocities result in shorter dwelling times in the jet and, subsequently, reduced heat transfer. Main arc gas flow $\left[1 \cdot \mathrm{min}^{-1}\right]$ is an important factor influencing both the plasma jet temperature and velocity. Higher main gas flow is expected to give rise to higher velocities of the particles. Main gas is partially used for cooling the SG-100 gun. Auxiliary arc gas flow $\left[1 \cdot \mathrm{min}^{-1}\right]$, used for additional stabilization of the plasma arc and extended heat transfer, is usually lower than the flow of main gas and is therefore expected to have a lesser impact on the in-flight particle properties. The carrier gas flow $\left[1 \cdot \mathrm{min}^{-1}\right]$ is a critical factor for determining the trajectories of the particles withing the plasma jet. Too low carrier gas flow could result in particle bouncing off the jet rather than penetrating it while too high value of carrier gas could cause the particles to intersect the plume and travel on the other periphery. Also, the flow of a carrier gas contributes to the total flow of gases in the plasma gun orifice. Linked to the carrier gas flow parameter, powder hopper revolutions per minute [1] influence the amount of powder entering the plasma jet. An increase in the amount of powder entering the jet could lead to decrease in average temperature and velocity of the particles, respectively (identical amount of heat and momentum distributed to a higher number of particles). Last factor selected for investigation is not directly set by the system control module. However, due to a presence of steep space gradients in temperature and velocity of the jet, spray distance $[\mathrm{mm}]$ is one of the key factors influencing the powder particles dwelling time in the jet and determines the amount of heating and acceleration the particles undergo.

\subsection{In-flight Properties}

\subsubsection{Taguchi design of Experiment}

The full-factorial design of in-flight properties measurement experiment for the selected six (threelevel) factors would entail $3^{6}=729$ measurements. Furthermore, such processing does not take into consideration the potential interactions between the factors, a phenomena likely to occur during plasma spray process (e.g. a mutual interaction between the flow of the particular gases). Taguchi design of experiment [21] was therefore chosen as a suitable technique to accomplish the task. The statistical concept of the Taguchi's design effectively combines the individual factor levels, resulting in high efficiency of the experimental design, i.e. it maintains the primary information yield while reducing the number of trial runs significantly.

For the case of six three-level factors (used in this study), the corresponding standardized orthogonal array is L-18 (L18). Following the L-18 design, the number of necessary trial runs is reduced from 729 to 18. With respect to the number of factors, number of levels per each factor, the anticipated mutual bonds, results reliability and variations or repeatability of the process, the standardized array had to be modified according to a described procedure [21] and the array columns were then assigned accordingly. The respective factors levels according to the modified array could be seen from Table 2. To furthermore increase the results reliability, two runs per combination were carried out and all runs were carried out in random order.

Analysis of variance ("ANOVA") of the results obtained from Taguchi design was carried out. ANOVA is a statistical, decision-making tool for detecting changes in average performance of measured data. By comparing the variations of the data measured at different factor levels with the overall variation changes, ANOVA determines the credibility of measured data sets and respective factors influences. To ascertain 
the influences of particular factors on the in-flight temperature and velocity of HA powder particles, ANOVA results were used to determine a percent contribution of every factor to the overall changes at the selected ranges.

It has to be noted that despite its advantages over other general designs, the determination of single parameter's influence is less demonstrable in Taguchi design.

\subsubsection{In-flight Measurement Tools}

To detect the particles and determine their respective properties during the deposition, a fast-shutter CCD laser-assisted camera was used (Oseir Ltd., Tampere, Finland). Orthogonal pattern of the setup was used, i.e. the axis of the plasma jet was perpendicular to the camera lens and laser emission axes (Fig. 3).

During the study, it was found that the automatic mode of the camera system has an influence on the measured data (measured average values were found to be linked to the settings of the camera exposure time). As in the automatic mode the camera parameters are changed frequently in order to capture the maximum number of particles, the data obtained within one measurement set experience offset shifts due to the settings changes. To ensure increased credibility of the results with respect to the relative differences in the measured properties, manual detection mode with a constant shutter time of $15 \mu \mathrm{s}$ was therefore used for all measurements. The manual settings of the detection parameters resulted in a lower number of detected particles per 1 second. The data of detected particles were therefore collected for a period of at least 1 minute for each run. The total statistics (number of captured particle for each run) was no lower than 200 particles per run of the system.

Furthermore, the camera focus distance was set further from the plume to $235 \mathrm{~mm}$, in order to detect the entire volume of the plasma jet at any given spray distance.

\subsection{Coatings Production and Characterization}

Based on the obtained results of the in-flight properties, six combinations were selected for subsequent coating deposition (denoted as A-F, Table 3). The objective of the selection was to represent the extreme values of the HA powder in-flight properties, i.e. to deposit coatings under low-medium-high in-flight temperature/velocity (Fig. 4).

Coatings were deposited using 15 passes of a robotic arm moving at a transverse speed of $100 \mathrm{~mm} \cdot \mathrm{s}^{-1}$. The substrates used in this study were platelets $(29 \times 24 \times 2.5) \mathrm{mm}$ of Ti-6Al-4V alloy conforming to ASTM F136 Grade 5 standard. The substrates were chemically degreased and grit blasted using standardized uniform procedure with constant angle, distance and dwelling time (roughness $R_{a}=5.07 \pm 0.32 \mu \mathrm{m}$ )

The sprayed samples were embedded into a two-component resin, ground and polished and their microstructure was investigated using SEM.

X-ray diffractometry spectra of the coatings were obtained and assessed using Rietveld analysis [20]. This allowed a quantitative analysis of the phase compositions of the produced coatings.

To obtain unbiased information, various techniques were used to assess the porosity of the produced plasma sprayed coatings with respect to the porosity of the initial HA powder feedstock. Software image analysis of the polished SEM samples and helium pycnometry methods were used for internal porosity evaluation, while mercury intrusion porosimetry provided information on the open porosity.

Surface roughness indicators were measured according to ISO: 4287 - 1984 standard. Mean deviation of the profile $\left(R_{a}=\frac{1}{n} \sum\left|y_{i}\right|\right)$ and root-to-mean square deviation $\left(R_{q}=\sqrt{\frac{1}{n} \sum y_{i}^{2}}\right)$ indicators were measured in two perpendicular directions to affect the potential effect of the spray gun movement direction.

Five loading and unloading cycles (sample unloaded to $90 \%$ of the current load) were used for one micro-hardness indentation. Ten indentation per sample were carried out and provided data on microhardnesses and elastic moduli of the produced coatings.

In-house-made shutter-apparatus was used to capture the single splats of the HA powder onto polished Ti-6Al-4V surfaces. The conditions for deposition of the splats were set identically to the six combinations selected for coatings deposition. The size of the prepared polished substrates was selected so as to collect particles from hot middle of the plasma jet as well as from its periphery to comprehend the variations in temperatures and velocities within the jet. Splat types with the highest occurrences for the given sample set were investigated (shape, morphology and splashing behavior). 


\section{Results \& Discussion}

\subsection{In-flight Properties}

The measured average in-flight temperatures and velocities of the HA powder particles could be seen from Table 2 and Fig. 4, including their respective measured standard deviations. It was found that the temperatures of the particles during deposition (within a range of $2294 \mathrm{~K}-2708 \mathrm{~K}$ ) were above the incongruent decomposition point of hydroxyapatite $(1843 \mathrm{~K})$. The velocities of the HA particles reached from $152 \mathrm{~m} \cdot \mathrm{s}^{-1}$ to $291 \mathrm{~m} \cdot \mathrm{s}^{-1}$, i.e. for an average diameter of $39.90 \mu \mathrm{m}$, the kinetic energy of impinging particles could differ by $\sim 270 \%$. Analysis of variances of the measured properties according to Taguchi design allowed to determine particular influences of the six selected parameters. The relative strengths of the six factors influences on the in-flight properties could be seen from Fig. 5. It could be seen that for the selected applied ranges of the particular parameters, spray distance is the most influential factor for both temperature and velocity of the particles. To quantify the effect, a single measurement was carried out: the system was set and run according to the combination 18 from Taguchi design (Table 2) and the in-flight properties were measured at $75 \mathrm{~mm}$ to $125 \mathrm{~mm}$ spray distance range. It was found that the temperature dropped by $265 \mathrm{~K}$ while the velocity dropped by $83 \mathrm{~m} \cdot \mathrm{s}^{-1}$ with the increase from $75 \mathrm{~mm}$ to $125 \mathrm{~mm}$ position.

Dyshlovenko et el. [11] carried out a full-factorial experimental work on the influence of four selected parameters (electric arc power, composition of $\mathrm{Ar}+\mathrm{H}_{2}$ forming gas, spraying distance and mode of spraying - water vs. substrate). The coatings were then sprayed using a constant $100 \mathrm{~mm}$ distance and it was reported that the most influential parameter with respect to the crystalline phase and phase content of the coatings is the net power. This is in good agreement with the phase changes observations described in 3.2 .2

Based on the results, six combinations of the system parameters were selected for coating production (denoted as A - low temperature, low velocity to F - high temperature, high velocity, Figure 4). The maximum differences of the measured in-flight properties were $355 \mathrm{~K}$ and $98 \mathrm{~m} \cdot \mathrm{s}^{-1}$ (samples $\mathrm{A}$ and $\mathrm{F}$ ), expected to give rise to different coating properties. To facilitate easier orientation in the following text, a summary of the in-flight properties of the six selected samples is provided in Table 3.

\subsection{Coating Properties}

\subsubsection{Microstructure}

The top layer morphology and cross-section of the produced coatings could be seen from Fig. 6 and Fig. 7, respectively. The analysis of the images revealed that the microstructure of the coatings is dependent on both the in-flight properties of the particles. The investigation of the coatings crosssections revealed a change in the morphology (from fused-type towards the individual splats structures) with increasing temperature and decreasing velocity of the particles. Contrary to general accordance [12], the higher temperatures of the impinging HA particles (samples B, D, F) resulted in individual splat structure of the coatings separated by the typical void chains while the lower temperature particles (A, E) gave rise to bulk-type coatings with no distinct splats observed and relatively low porosity of spherical nature. This seeming disagreement could be explained by the decreasing in-flight velocity of the particles: in general, the lower the particle velocity, the less fused morphology of the produced coating. Sample $\mathrm{C}$ (in-flight temperature in-between that of samples E, D) composed of fused coating with some individual splats structure in the vicinity of the interface, in accordance to the obtained results and suggested joint influence of in-flight temperature and velocity.

A network of relatively short vertical micro-cracks was found in low temperature sample coatings (A, E). Additionally, horizontal macro-cracks were observed in the coating E. As the horizontal macro-cracks were observed in the middle of the coating layers deposited by individual gun passes, they are most likely not the consequence of the pauses between the passes, but could be a consequence of coalescence of micro-cracking for stress alleviation during the cooling phase instead.

\subsubsection{Phase Composition}

The Rietveld analyses of the measured XRD spectra indicated that the phase content changed substantially after the deposition process. As could be seen from Table 1, significant phase content changes were found in the coatings, with the loss of original HA phase of up to $76 \%$ as compared to original HA 
feedstock (sample A). No distinct relation between in-flight temperature or velocity and the percentage loss of the HA phase was found. Recrystallization of the initial HA phase presumably occurred in the coatings as the calculated preferred orientations of the crystallographic planes of hydroxyapatite within the samples were calculated as $\left(\begin{array}{lll}0 & 2 & 1\end{array}\right)$ and $\left(\begin{array}{lll}0 & 0 & 4\end{array}\right)$ as compared to initial $\left(\begin{array}{lll}0 & 1 & 0\end{array}\right)$ and $\left(\begin{array}{lll}0 & 0 & 2\end{array}\right)$ planes.

Clear trend was, however, observed for the content of $\mathrm{CaO}$ phase in the coatings: with increasing in-flight temperature of the particles, the content of $\mathrm{CaO}$ was decreasing (Fig. 8). Detrimental CaO phase content increased to up to $14.6 \%$ in sample A, yielding such coating unacceptable for biomedical applications. Low $\mathrm{CaO}$ content $(\leq 2.6 \%)$ was obtained in high in-flight temperature samples $(\mathrm{B}, \mathrm{F})$.

In accordance with Lugscheider et al. [22], metastable tri-calcium and tetra-calcium phosphate phases ( $\alpha$-TCP, $\beta$-TCP, TTCP) developed during the spray process, altering the functional reliability of the coatings for biomedical use. TCP content varied from $13.3 \%$ to $19.4 \%$ and did not follow any trend with respect to the in-flight properties. The content of TTCP in the produced coatings was the highest among other calcium phosphate phases and arguably the phase change from HA to TTCP is the most favored during the spray process when reaching temperature necessary to initiate such change $\left(\mathrm{T}_{1}\right)$. Markedly lower content of TTCP phase was detected in the two high-temperature samples (B, F; Fig. 8). In the two samples, calcium pyrophosphate $[\mathrm{CPP}]$ phases presence was detected instead $(13.2 \%$ and $35.6 \%$, respectively). It is therefore suggested that the temperatures above certain level $T_{2}$ induce further transformation (3).

$$
H A \stackrel{\text { above } \mathrm{T}_{1}}{\longrightarrow} T T C P \stackrel{\text { above } \mathrm{T}_{2}}{\longrightarrow} C P P
$$

Using the obtained data, we can stipulate that the temperatures

$$
\begin{array}{r}
T 1 \leq 2350 K \\
2350 K \leq T 2 \leq 2520 K
\end{array}
$$

in (3). Literature indicates the lowest temperature for phase transformation from HA to TTCP as $1820 \mathrm{~K}$, i.e. lower than the values measured during the spraying process [18].

According to Brown [23] and the CaO- $\mathrm{P}_{2} \mathrm{O}_{5}-\mathrm{H}_{2} \mathrm{O}$ ternary diagrams derived by Harris [18], the CPP phases are "CaO deficient" as compared to TTCP phase $(\leq 54 \mathrm{wt} \% \mathrm{CaO}$ as compared to $\geq 57 \mathrm{wt} \% \mathrm{CaO}$; at vapor pressure $67 \mathrm{kPa}$, Fig. 9). Retaining the CPP phases upon cooling to the room temperature would therefore be accompanied by a drop in $\mathrm{CaO}$ content, a phenomenon observed in the two coatings. It is necessary to note that the results are based on the selection of the nine considered calcium-phosphate phases and potential existence of another phase not involved in the performed Rietveld analysis could influence the phase transformation processes. Also, given the phase changes under the selected spray conditions, the produced coatings would not be acceptable for tissue integration and utilization for prostheses mainly due to the significant loss of HA content.

\subsubsection{Porosity}

For plasma spray technology coatings, internal porosity levels of $2-20 \%$ are indicated in the literature [16]. The measured internal porosity of the coatings produced in this study as assessed using two methods (Table 4) was $7-17 \%$. Such porosity levels fall within the $5-20 \%$ range indicated as suitable for osteoblast cells proliferation [15].

The measured coating internal porosities are slightly higher than the porosity determined for the powder feedstock $(8.0 \%)$, indicating further formation of internal porosity (spherical pores or void chains) in the coatings. No significant trend between the in-flight properties and the internal porosity levels was determined. However, the SEM image analysis indicated that the samples produced under low in-flight temperature (A, 6.9\%; E, 8.3\%) contained lower porosity levels as compared to their higher-temperature counterparts. This is probably a consequence of different morphology of the coatings: samples A, E exhibited fused-like type of coatings, resulting in isolated spherical porosity (yielding low internal porosity values) as compared to the void channels in the other coatings. This trend was not confirmed by the subsequent helium pycnometric method. The principle of the helium pycnometric method consists in filling the well-defined volume containing the powder sample with helium gas and measuring the loss of gas volume in an interconnected chamber. Obtained value provides an information on true density of the sample material and its respective porosity (based on the theoretical value of bulk density of HA 
$\rho=3.156$ g. $\mathrm{cm}^{-3}$ ). Given the measured accuracy of the method (porosity of one sample measured by several repetitive runs exhibited maximum difference of $0.66 \%$ ), the difference in the measured values as compared to SEM determination was probably caused by the the inability of the pycnometric method to differentiate between the spherical porosity of bulk-like coatings A, E and the interconnected chains of voids in the splats structure of samples B, F and the inflow of helium into the open micro-cracks of the coatings.

It was found that the open porosity of the coatings (as measured by mercury intrusion method) is significantly higher for the low in-flight velocity samples (A $22.4 \%$, B $27.9 \%$ ), i.e. the higher kinetic energy of fast-moving particles probably contributed to a decrease in the open porosity content. Similarly, the lowest open porosity content was measured for the two highest in-flight temperature samples (E 9.8\%, F $8.8 \%)$.

The SEM image analysis method allowed specification of the average pore sizes. From the results, average pore diameters were subsequently calculated assuming circular geometry of the pores. The obtained data suggest that with increasing in-flight temperatures of the particles, the average pore size decreased in the final coatings. However, the absolute differences are not significant and the measurement could be influenced by the fact that the geometrical approximation may not be correct in the case of void chains observed in coatings B, D and F. The literature views on the optimal pore size for successful bone in-growth vary, however, the measured values of the pore diameters of the produced HA coatings appear undersized for such application, yielding the coatings unsuitable for bone tissue in-growth [15].

\subsubsection{Surface Roughness}

The results of the roughness measurements for HA coatings could be seen from Table 5 . No influence of the in-flight velocity was confirmed and no clear trend could be distinguished, i.e. the kinetic energy of the particles did not contribute to the overall surface roughness. It was found that the highest in-flight temperature sample $(\mathrm{F})$ retained the lowest levels of roughness $(7.4 \mu \mathrm{m})$. The inferior value of the surface roughness could be explained by the splat formation behavior due to the rapid solidification from the high temperature. This phenomena results in a formation of smooth flattened splat surface with radial tails and is further discussed in the section 3.2.6.

\subsubsection{Elastic Moduli \& microhardness}

Micro-hardness of HA plasma deposited coatings was assessed. Ten indentations were carried out per sample, each consisting of five loading and unloading cycles under increasing force. Average values of the ten indentations were considered as the measured hardness of the sample. The indentations provided information on the respective coatings moduli. The results could be seen from Table 6 .

The samples deposited under low in-flight velocities (A, B) exhibited the highest levels of material hardness (1.16 GPa and 0.86 GPa, respectively). This result in not in accordance with the prevalent idea of increased hardness coatings deposited by means of build-up of high kinetic energy particles [24]. Furthermore, no clear trend between the micro-hardness of the coatings and their respective porosity levels was observed. It should be noted that the measured levels of micro-hardness are lower than the values generally indicated for plasma sprayed ceramic coatings.

In correlation with the micro-hardness measurements, it was found that the highest moduli among the HA coatings exhibited the low in-flight velocity samples (A, 35.5 GPa and B, 26.8 GPa). No dependence of both coating characteristics on the in-flight temperature of the HA particles was confirmed as the values did not follow any clear trend.

\subsubsection{Single splats}

In thermal spray processes, morphology, shape, spreading and solidifications behavior of single splats substantially influence the characteristics of the final coatings [25]. A number of characteristics are predominantly influenced by the first deposited layer. Single splats (from molten or semi-molten droplets) were deposited onto mirror-polished Ti-6Al- $4 \mathrm{~V}$ surface under conditions identical to the coatings deposition setup (A - F, Fig. 10).

The SEM analysis showed significant differences in average shapes and morphologies of the splats sprayed under different spray conditions. It was found that the splashing behavior of the particles is influenced mainly by the in-flight velocity. Contrary to the expected influence of the kinetic energy of 
the particles, the lower in-flight particle velocity samples (A $152 \mathrm{~m} \cdot \mathrm{s}^{-1}$, B $183 \mathrm{~m} \cdot \mathrm{s}^{-1}$ and D $205 \mathrm{~m} \cdot \mathrm{s}^{-1}$ ) resulted in splashed shapes. Among the three, the intensity of splashing was found to be influenced by the in-flight temperature: the higher the in-flight temperature of the particles, the higher the degree of splashing within the three samples subset. The splashed tails ranged from relatively short (sample A) to a network of long, non-interconnected tails spanning the entire deposition area (sample B). The high in-flight velocity samples (C $242 \mathrm{~m} \cdot \mathrm{s}^{-1}, \mathrm{~F} 250 \mathrm{~m} \cdot \mathrm{s}^{-1}$ and E $279 \mathrm{~m} \cdot \mathrm{s}^{-1}$ ) form a second subset of non-splashed, predominantly round splats with no (C, E) or limited (F) splashing at its peripheries. As in the case of the former subset, the in-flight temperature was the secondary factor determining the final morphology of the splats. The low in-flight temperature sample E contained mostly round splats with notable rim around their periphery while the high temperature sample $\mathrm{F}$ contained minor radial splashed tails. The sample F (high velocity, high temperature) contained micro-cracks within the deposited splats.

Dhiman et al. [26] suggested a dimensionless solidification parameter $\Theta$ defined as the ratio of solidified part to overall splat thickness during the solidification process. The parameter incorporates a number of factors. Among others, the impact velocity of particles and thermal contact resistance between splats and surface are considered. It was suggested that there are three different conditions determining the behavior during impact and solidification:

1. for $\Theta \ll 1$, i.e. low impact velocities, the splats will spread into a thin sheet liquid and rupture internally, leading to extensive fragmentation, producing a small central splat surrounded by a ring of debris; in our study, the three low velocity samples (A, B, D) meet these criteria and are characterized by the said splat morphology

2. for $\Theta \sim 0.1$ to 0.3 , i.e. high impact velocities, the significant growth of solid layer restricts the splats from spreading too far; in our study, splats of the samples C, E follow this trend

3. for $\Theta \sim 1$ the rapid solidification obstructs the spreading liquid and round splats with radial tails are created; as this was observed in our study for sample F (high velocity, high temperature), it is suggested that the particle temperature aided in a further increase of the value $\Theta$, which resulted in a formation of the radial tails at the rim of the splats

In agreement with the study [26], the observed morphologies of the collected single splats are most likely influenced mainly by the impact velocity of the HA particles, the solidification behavior is however additionally influenced by the in-flight temperature of the particles and the thermal contact resistance of the two materials (HA, Ti-6Al-4V).

\section{Conclusions}

Bioactive HA coatings were deposited onto Ti-6Al-4V substrates under different average in-flight temperatures and velocities. Relative differences in the microstructure, phase composition, porosity levels, surface roughness, micro-hardness and coating moduli were investigated with respect to the inflight properties. From the results it can be concluded that:

1. The in-flight characteristics are substantially influenced by the setting of the system parameters; the dominant factor was found to be the spray distance - with a change from $75 \mathrm{~mm}$ to $125 \mathrm{~mm}$, the temperature and velocity dropped by $265 \mathrm{~K}$ and $83 \mathrm{~m} \cdot \mathrm{s}^{-1}$, respectively

2. The microstructure of the deposited coatings is influenced by the in-flight temperature and velocity of the particles; contrary to other literature, the high temperature particles $(\geq 2500 \mathrm{~K})$ resulted into individual splat morphology with interconnected void chains in the coatings while low temperature particles $(\leq 2470 \mathrm{~K})$ gave rise to a bulk type well fused coatings; this fact could be explained by a joint incidence of the in-flight kinetic energy of HA particles (velocity)

3. The phase composition of the coatings differs substantially from the initial powder feedstock; the loss of HA phase could account for $76 \%$; the amount of detrimental $\mathrm{CaO}$ phase in the coatings is inversely proportional to the in-flight temperature of HA particles; majority of HA phase was transformed into TTCP phase, presumably the favored HA phase change during plasma spraying; the highest in-flight temperature samples contained some CPP phase and the amount of TTCP phase was lowered - it has been suggested that some of the TTCP could have changed into the CPP phases under certain conditions 
4. The produced coatings contained $7 \%-20 \%$ porosity levels, suitable for hard tissue applications, however, the pore sizes were too small for bone tissue in-growth; the open porosity of the coatings was found to be a function of the in-flight velocity of the particles, with faster particles giving rise to lesser open porosity

5. The surface roughness of the deposits was found found to vary from $R_{a}=7.4-19.4 \mu \mathrm{m}$; the highest temperature particles (F) resulted in the most smooth surface $\left(R_{a}=7.4 \mu \mathrm{m}\right)$ probably due to joint incidence of the in-flight velocity, thermal contact resistance and in-flight temperature

6. Low in-flight velocity particles (A, B) resulted in coatings with superior micro-hardness and elastic moduli as compared to their "faster" counterparts (average micro-hardness, elastic moduli of 1.01 GPa, 31.2 GPa vs. average 0.22 GPa, 17.2 GPa of samples C - F)

7. It was shown that the shape, morphology and splashing behavior of single splats deposited on polished surfaces is mainly influenced by the in-flight velocity of the impinging particles; in-flight temperature was found to be a secondary factor influencing mainly the extent of splashing of the individual splats

\section{Acknowledgments}

The authors would like to thank Dr Ondrej Kovarik from Department of Materials, Faculty of Nuclear Sciences and Physical Engineering, Czech Technical University for his valuable comments and discussion during the evaluation phase of the project. 
[1] L.L. Hench, J Am Ceram Soc, 74 (7), 1991, 1487-1510

[2] R.Z. Legeros, J.P. Legeros, Advanced Series in Ceramics, 1, 1993, 139-180

[3] K.A. Gross, V. Gross, C.C. Berndt, J Am Ceram Soc, 81 (1), 1998, 106-112

[4] W.R. Lacefield: Advanced Series in Ceramics, 1, Singapore, 1993, 223-238

[5] K.A. Khor, Y.W. Gu, C.H. Quek, P. Cheang, Surf and Coat Technol, 168 (2-3), 2003, 195-201

[6] J. Cizek, K.A. Khor, Z. Prochazka, Mat Sci Eng C, 27 (2), 2007, 340-344

[7] K. Gross, C.C. Berndt, H. Herman, J Biomed Mater Res, 39, 1998, 407-414

[8] R. Jaworski, L. Pawlowski, C. Pierlot, F. Roudet, S. Kozerski, F. Petit, J Therm Spray Technol, 19 (1-2), 2010, 240-247

[9] S. Beauvais, V. Guipont, F. Borit, M. Jeandin, M. Espanol,K.A. Khor, A. Robisson, R. Saenger, Surf and Coat Technol, 183, 2004, 204-211

[10] S. Dyshlovenko, B. Pateyron, L. Pawlowski, D. Murano, Surf and Coat Technol, 179, 2004, 110-117

[11] S. Dyshlovenko, L. Pawlowski, P. Roussel, D. Murano, A le Maguer, Surf and Coat Technol, 200, $2006,3845-3855$

[12] H. Li, K.A. Khor, Surf and Coat Technol, 201 (6), 2006, 2147-2154

[13] C.Y. Yang, R.M. Lin, B.C. Wang, T.M. Lee, E. Chang, Y.S. Hang, P.Q. Chen, J of Biomed Mater Res, 37 (3), 1997, 335-345

[14] H. Aoki: Medical Applications of Hydroxyapatite: Bone Mineral, Drug Delivery System, Cancer \& HIV, IVH \& CAPD, Dental Implant. Ishiyaku EuroAmerica, 1994

[15] K.A. Gross, W. Walsh, E. Swarts, J Therm Spray Technol, 13 (2), 2004, 190-199

[16] P. Fauchais, J Phys. D, 37 (9), 2004, R86-R108

[17] M.E. Pons, Developing Hydroxyapatite CAPS Coatings on Metallic Implants for Tissue Replacement, Nanyang Technological University, 2004

[18] D. Harris, Thermal Spray Research and Applications, 419-423, ASM International, 1991

[19] Y.J. Horng, H.H. Min, Biomaterials, 17 (21),1996, 2059-2064

[20] H.M. Rietveld, Acta Cryst, 22, 1967, 151-152

[21] G. Taguchi, Quality Engineering in Production Systems, McGraw-Hill, 1988

[22] E. Lugscheider, T.F. Weber, M. Knepper, Thermal Spray Technology: New Ideas and Processes, 337-344, ASM International, 1988

[23] P.W. Brown, J Am Ceram Soc, 75 (1), 1992, 17-22

[24] H. Li, K.A. Khor, P. Cheang, Surf and Coat Technol, 155 (1), 2002, 21-32

[25] P. Fauchais, M. Fukumoto, A. Vardelle, M. Vardelle, J Therm Spray Technol, 13 (3), 2004, 337-360

[26] R. Dhiman, A.G. McDonald, S. Chandra, Surf Coat Technol, 201 (18), 2007, 7789-7801 


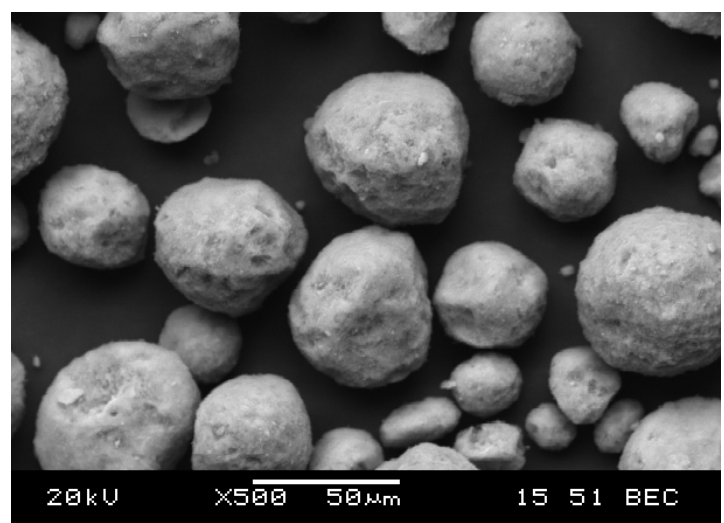

(a) HA powder

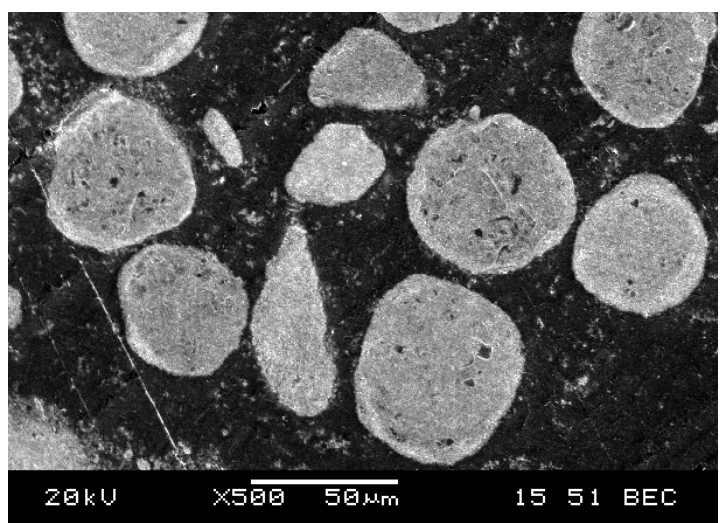

(b) HA powder cross-section

Figure 1: Produced HA powder

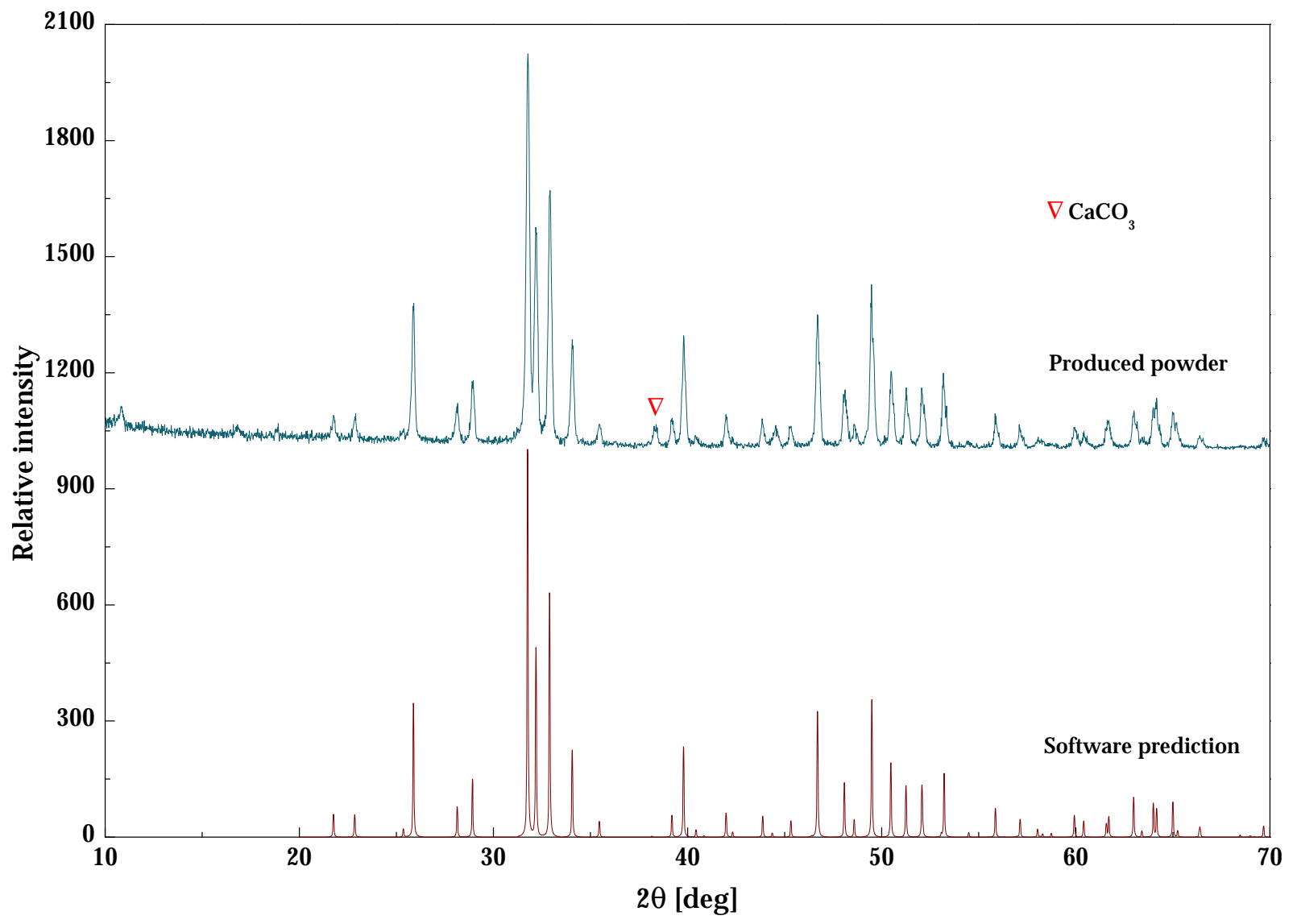

Figure 2: XRD pattern of produced HA powder 


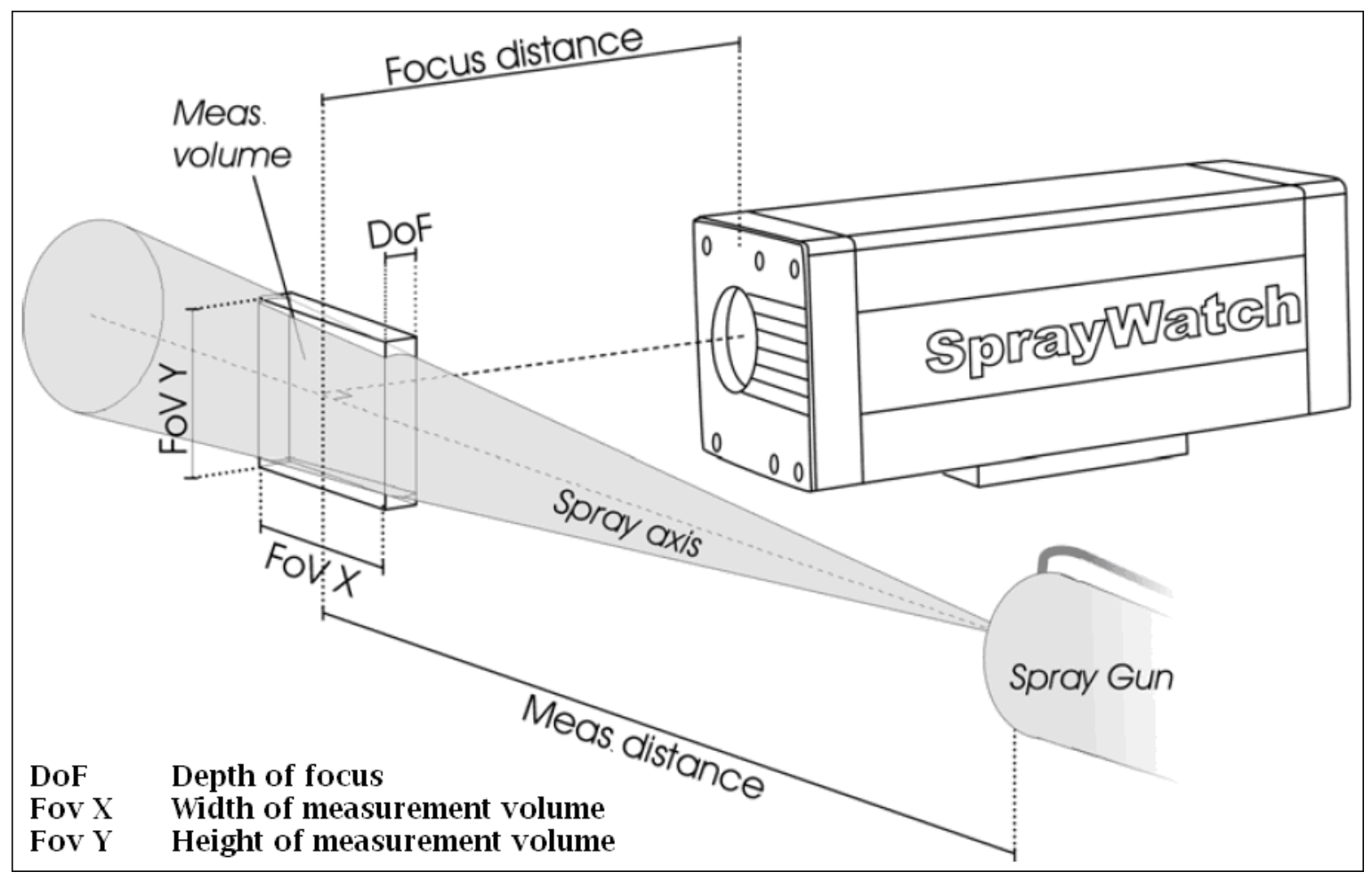

Figure 3: In-flight properties measurements setup

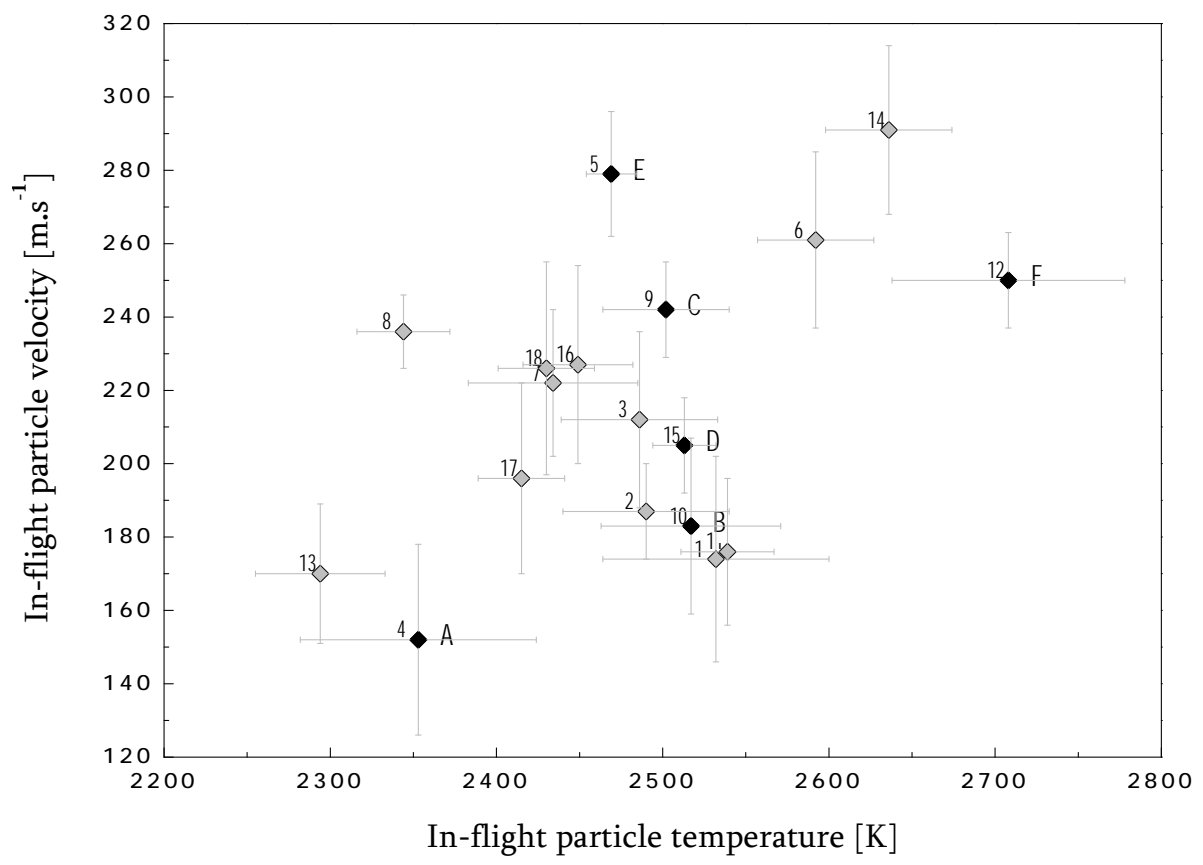

Figure 4: Six spray combinations for coatings production 
In-flight temperature

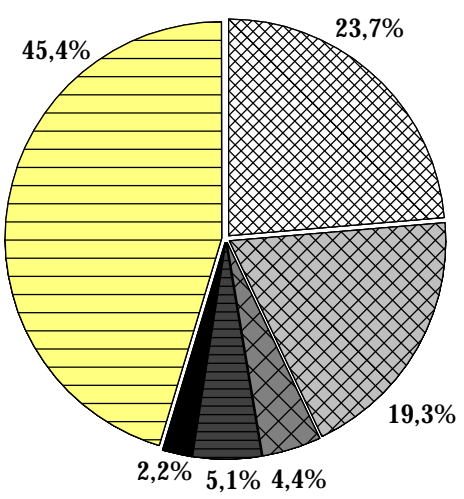

In-flight velocity

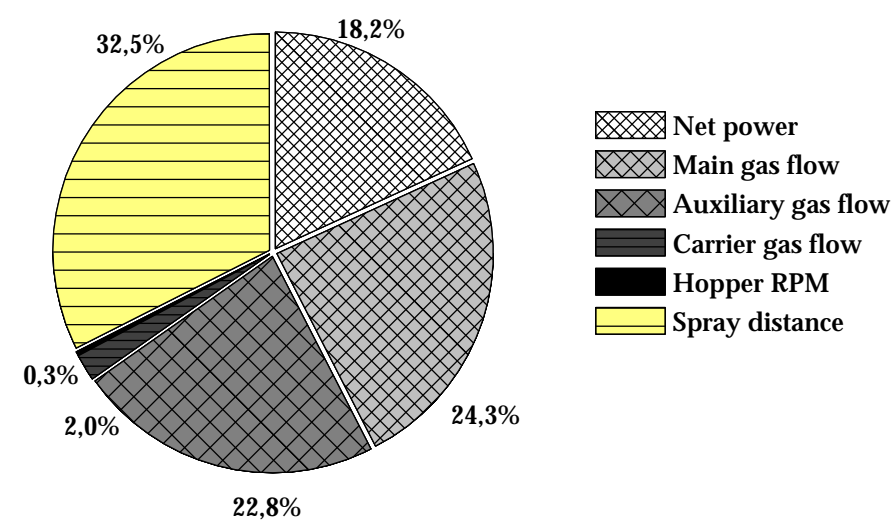

Figure 5: Relative influences of six selected factors on the in-flight properties of HA powder 


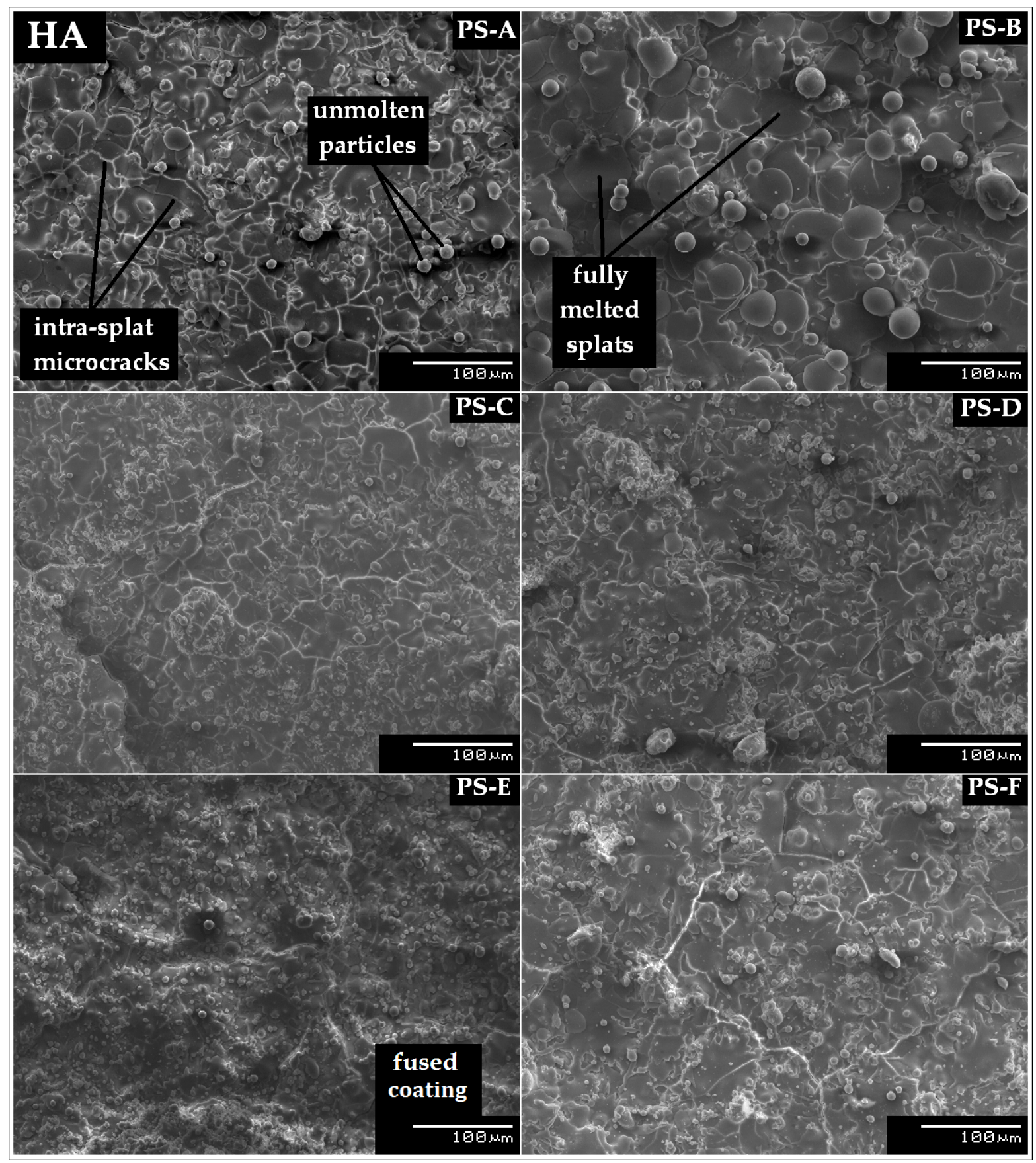

Figure 6: SEM images of produced coatings top layers 


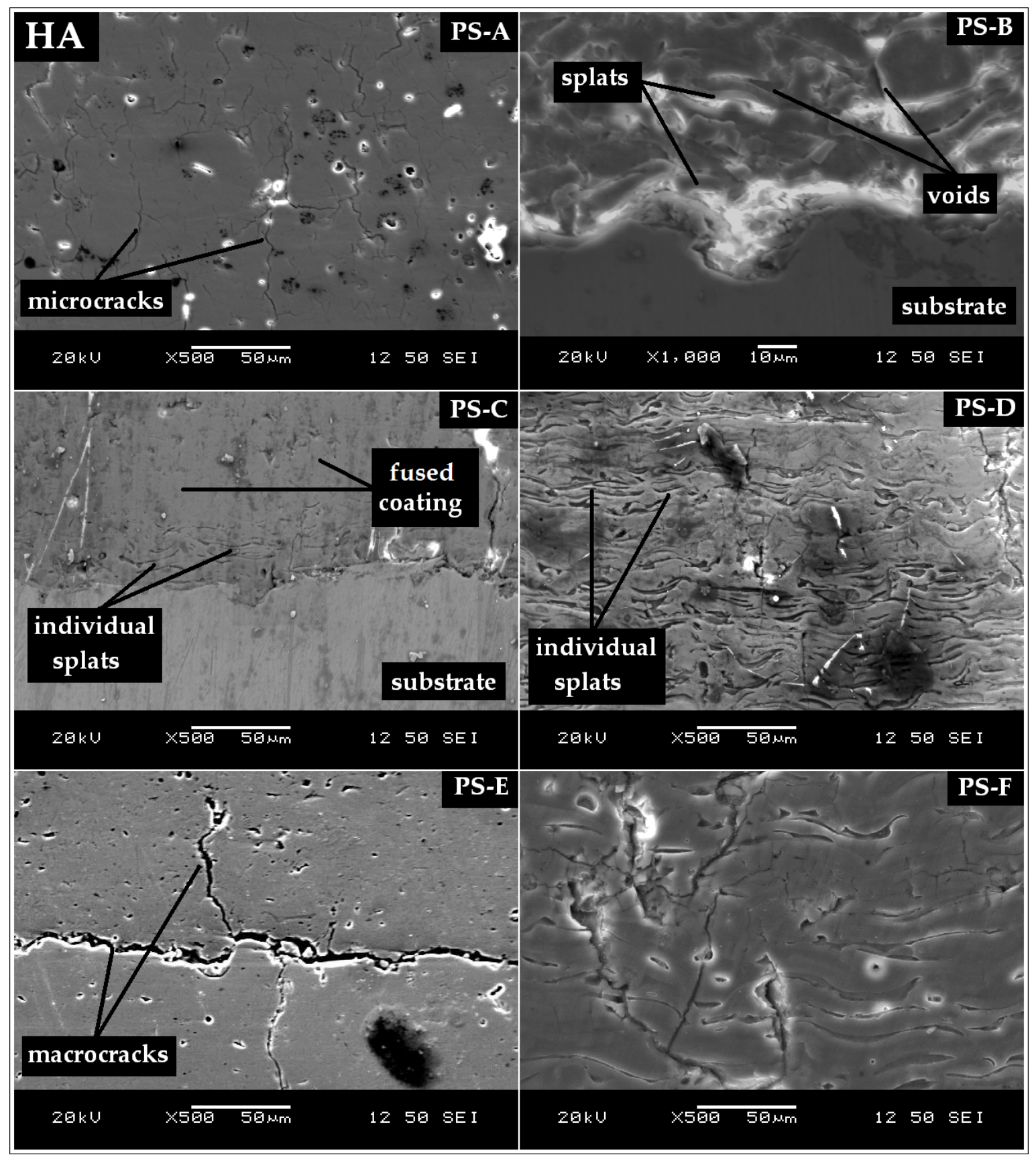

Figure 7: SEM images of produced coatings cross-sections 


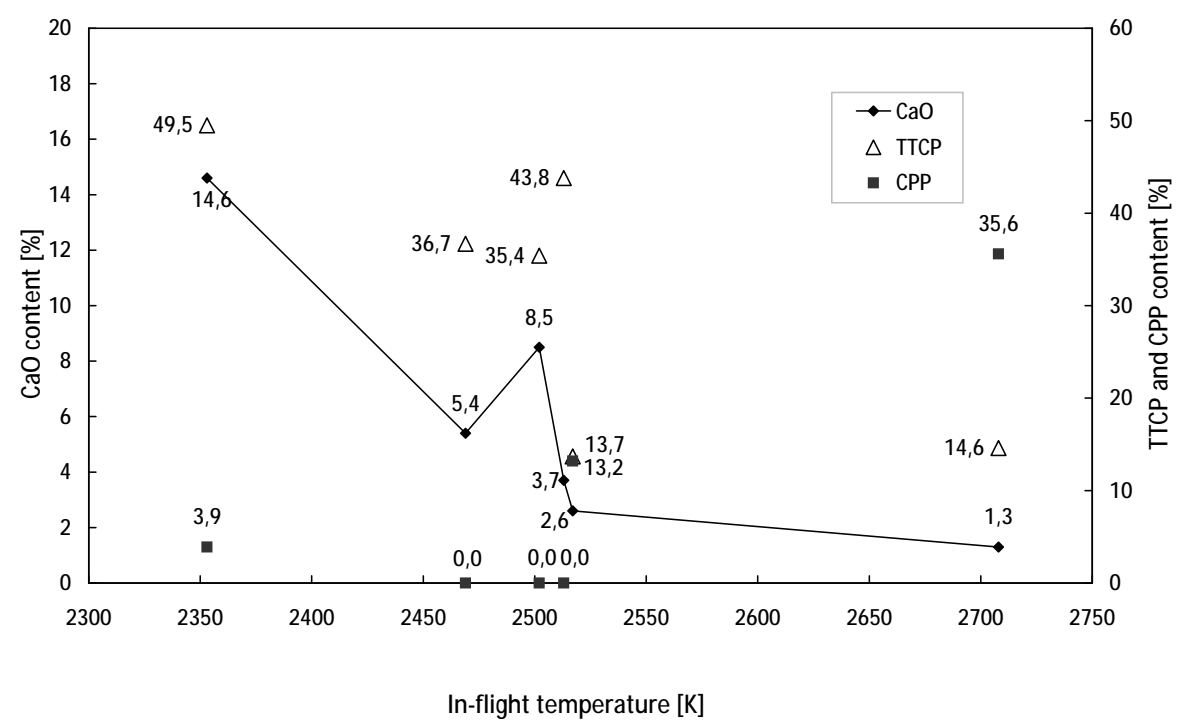

Figure 8: $\mathrm{CaO}$, TTCP and CPP content in produced HA coatings

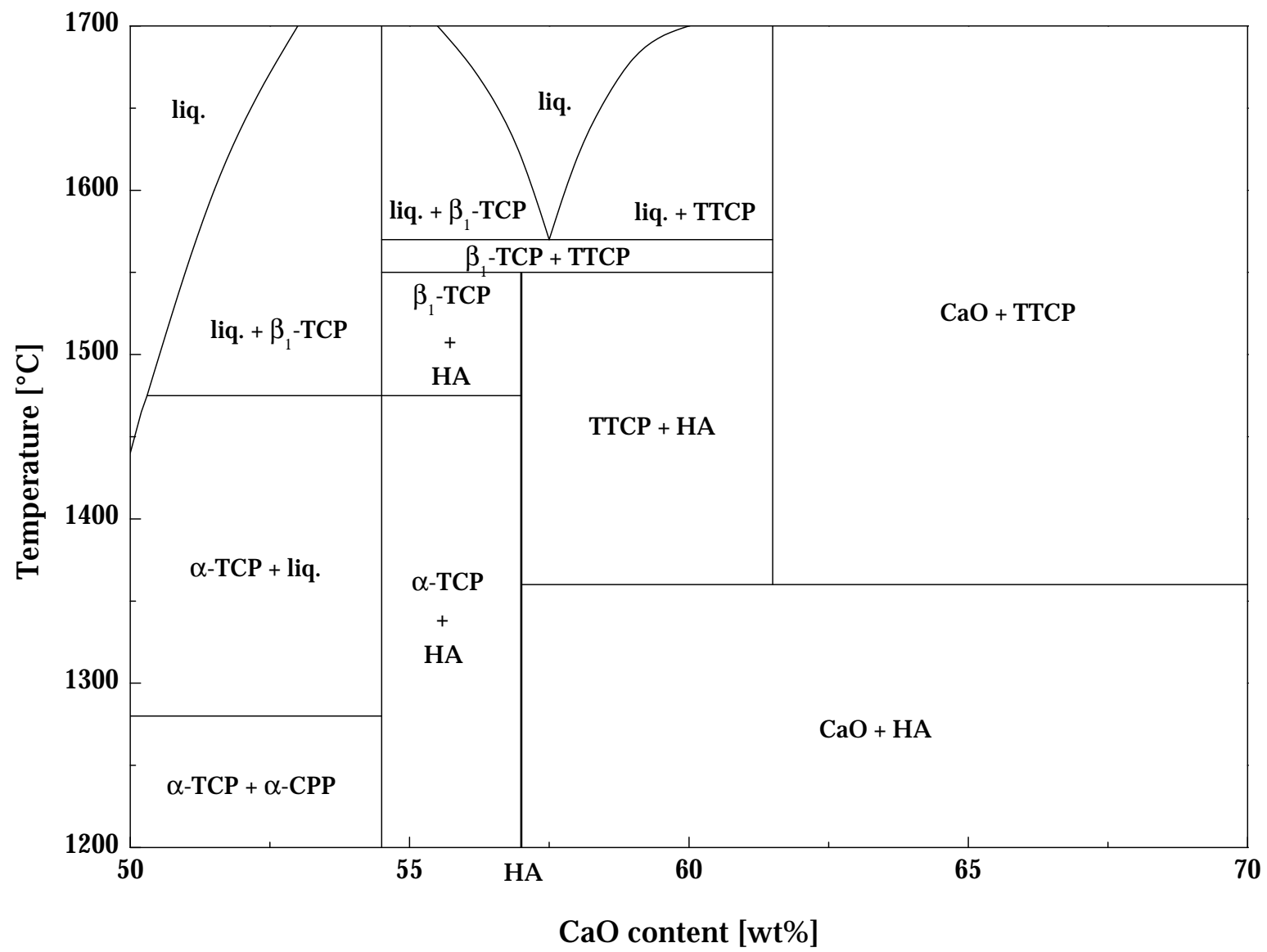

Figure 9: Phase diagram of $\mathrm{CaO}-\mathrm{P}_{2} \mathrm{O}_{5}$ at vapor pressure of $66.7 \mathrm{kPa}$ 

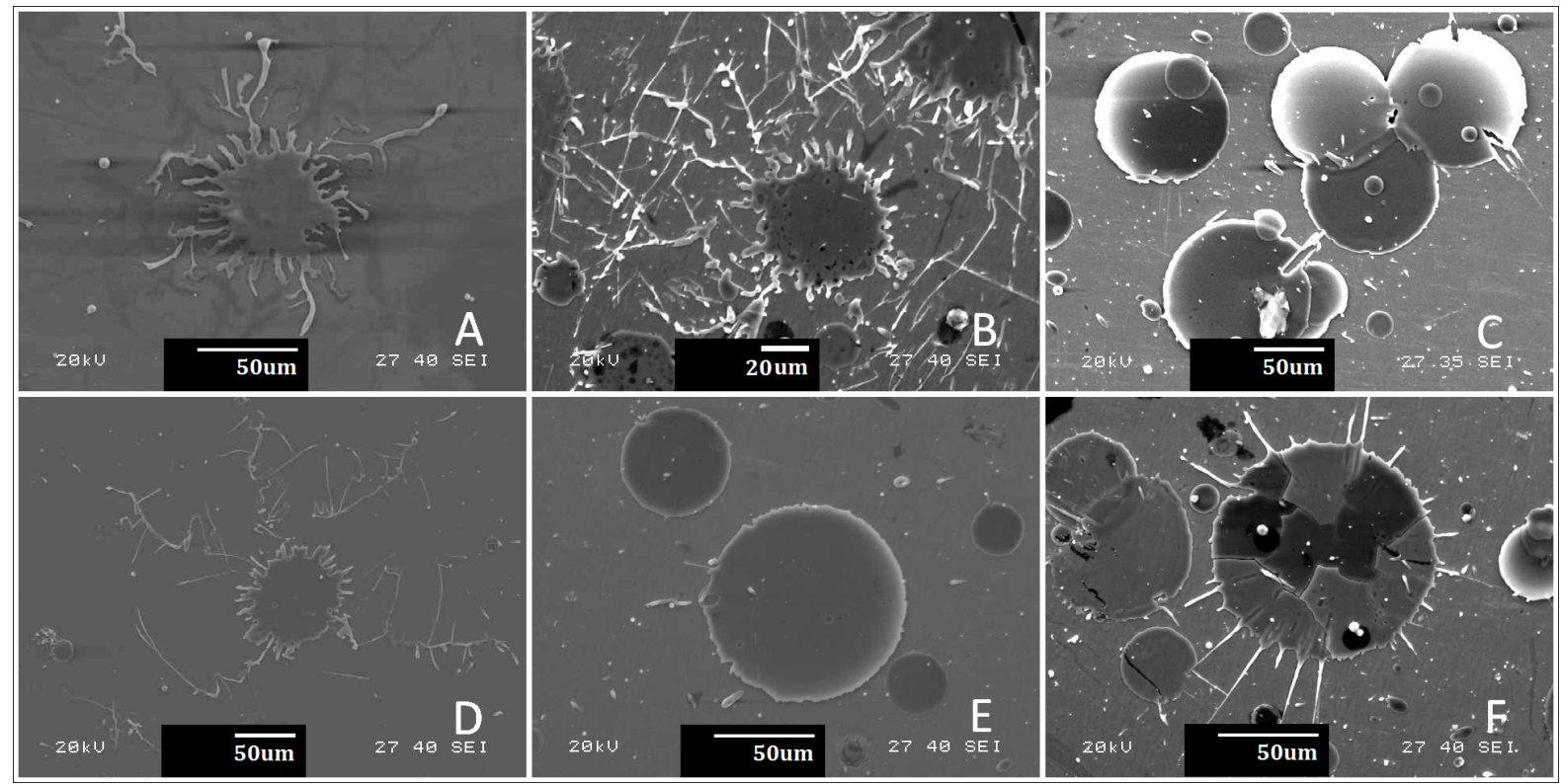

Figure 10: Plasma deposited HA splats on polished substrates

Table 1: Phase content of HA powder \& produced coatings

\begin{tabular}{lcccccccc}
\hline \multicolumn{3}{c}{ Phase } & \multicolumn{7}{c}{ Content [\%] } \\
& ICSD & Powder & \multicolumn{7}{c}{ Coatings } \\
& no. & & A & B & C & D & E & F \\
\hline $\mathrm{HA}$ & 26205 & 93.0 & 18.6 & 56.3 & 41.0 & 33.4 & 39.3 & 28.6 \\
$\mathrm{CaCO}_{3}$ & 73446 & 5.0 & - & - & tr. & tr. & - & - \\
$\mathrm{CaO}$ & 75785 & 1.0 & 14.6 & 2.6 & 8.5 & 3.7 & 5.4 & 1.3 \\
$\alpha-\mathrm{TCP}$ & 00923 & - & 2.1 & tr. & - & 7.3 & 4.0 & 12.1 \\
$\beta-\mathrm{TCP}$ & 97500 & - & 11.2 & 14.1 & 15.1 & 11.9 & 14.4 & 7.3 \\
$\mathrm{TTCP}$ & 02631 & - & 49.5 & 13.7 & 35.4 & 43.8 & 36.7 & 14.6 \\
$\alpha-\mathrm{CPP}$ & 22225 & 1.0 & 3.9 & 1.9 & - & - & tr. & 18.8 \\
$\beta-\mathrm{CPP}$ & 14313 & 1.0 & - & 11.3 & - & - & - & 16.8 \\
$\mathrm{Ca}(\mathrm{OH})_{2}$ & 15471 & - & - & tr. & - & - & - & 0.5 \\
\hline
\end{tabular}

Note: Phase content $<0.5 \%$ indicated as traces (tr.) 
Table 2: Taguchi design of in-flight properties measurements

\begin{tabular}{ccccccccc}
\hline Run & $\begin{array}{c}\text { Net } \\
\text { power } \\
{[\mathrm{kW}]}\end{array}$ & $\begin{array}{c}\text { Main } \\
\text { gas } \\
{\left[1 \cdot \mathrm{min}^{-1}\right]}\end{array}$ & $\begin{array}{c}\text { Auxiliary } \\
\text { gas } \\
{\left[\mathrm{l} \cdot \mathrm{min}^{-1}\right]}\end{array}$ & $\begin{array}{c}\text { Feed } \\
\text { rate } \\
{[\mathrm{RPM}]}\end{array}$ & $\begin{array}{c}\text { Carrier } \\
\text { gas } \\
{\left[\mathrm{l} \cdot \mathrm{min}^{-1}\right]}\end{array}$ & $\begin{array}{c}\text { Spray } \\
\text { distance } \\
{[\mathrm{mm}]}\end{array}$ & $\begin{array}{c}\text { Measured } \\
\text { temperature } \\
{[\mathrm{K}]}\end{array}$ & $\begin{array}{c}\text { velocity } \\
{\left[\mathrm{m} \cdot \mathrm{s}^{-1}\right]}\end{array}$ \\
\hline 1 & 7 & 20 & 10 & 2 & 3 & 75 & 2532 & 174 \\
2 & 7 & 34 & 24 & 3 & 5 & 100 & 2490 & 187 \\
3 & 7 & 48 & 38 & 4 & 7 & 125 & 2486 & 212 \\
4 & 11 & 20 & 10 & 3 & 5 & 125 & 2353 & 152 \\
5 & 11 & 34 & 24 & 4 & 7 & 75 & 2469 & 279 \\
6 & 11 & 48 & 38 & 2 & 3 & 100 & 2592 & 261 \\
7 & 15 & 20 & 24 & 4 & 3 & 100 & 2434 & 222 \\
8 & 15 & 34 & 38 & 2 & 5 & 125 & 2344 & 236 \\
9 & 15 & 48 & 10 & 3 & 7 & 75 & 2502 & 242 \\
10 & 7 & 20 & 38 & 3 & 7 & 75 & 2517 & 183 \\
11 & 7 & 34 & 10 & 4 & 3 & 100 & 2539 & 176 \\
12 & 7 & 48 & 24 & 2 & 5 & 125 & 2708 & 250 \\
13 & 11 & 20 & 24 & 2 & 7 & 125 & 2294 & 170 \\
14 & 11 & 34 & 38 & 3 & 3 & 125 & 2636 & 291 \\
15 & 11 & 48 & 10 & 4 & 5 & 75 & 2513 & 205 \\
16 & 15 & 20 & 38 & 4 & 5 & 100 & 2449 & 227 \\
17 & 15 & 34 & 10 & 2 & 7 & 100 & 2415 & 196 \\
18 & 15 & 48 & 24 & 3 & 3 & 125 & 2430 & 226 \\
\hline
\end{tabular}

Note: Feed rate indicated in revolutions of powder feeder wheel per minute

Table 3: In-flight properties of the six selected combinations

\begin{tabular}{ccc}
\hline Sample & $\begin{array}{c}\text { Temperature } \\
{[\mathrm{K}]}\end{array}$ & $\begin{array}{c}\text { Velocity } \\
{\left[\mathrm{m} \cdot \mathrm{s}^{-1}\right]}\end{array}$ \\
\hline A & 2353 & 152 \\
B & 2517 & 183 \\
C & 2502 & 242 \\
D & 2513 & 205 \\
E & 2469 & 279 \\
F & 2708 & 250 \\
\hline
\end{tabular}

The ordered sequence of samples with respect to in-flight temperature is: $T_{A}<T_{E}<T_{C}<T_{D}<T_{B}<T_{F}$ The ordered sequence of samples with respect to in-flight velocity is: $v_{A}<v_{B}<v_{D}<v_{C}<v_{F}<v_{E}$

Table 4: Porosity of produced coatings

\begin{tabular}{ccccc}
\hline Sample & $\begin{array}{c}\text { Porosity [\%] } \\
\text { Image } \\
\text { analysis }\end{array}$ & $\begin{array}{c}\text { Pycnometric } \\
\text { method }\end{array}$ & $\begin{array}{c}\text { Mercury } \\
\text { intrusion }\end{array}$ & $\begin{array}{c}\text { Average } \\
\text { pore size } \\
{[\mu \mathrm{m}]}\end{array}$ \\
\hline A & 6.9 & 9.4 & 22.4 & 3.36 \\
B & 12.8 & 12.8 & 27.9 & 2.50 \\
C & 12.0 & 9.5 & 10.1 & 2.72 \\
D & 17.0 & 8.8 & 11.5 & 3.17 \\
E & 8.3 & 10.7 & 9.8 & 3.28 \\
F & 15.2 & 9.1 & 8.8 & 2.53 \\
\hline
\end{tabular}


Table 5: Roughness levels of plasma sprayed HA coatings

\begin{tabular}{ccc}
\hline Sample & \multicolumn{2}{c}{ Roughness $[\mu \mathbf{m}]$} \\
& $R_{a}$ & $R_{q}$ \\
\hline $\mathrm{A}$ & 11.3 & 14.9 \\
$\mathrm{~B}$ & 9.8 & 12.4 \\
$\mathrm{C}$ & 19.4 & 23.8 \\
$\mathrm{D}$ & 12.4 & 15.7 \\
$\mathrm{E}$ & 13.9 & 17.2 \\
$\mathrm{~F}$ & 7.4 & 9.4 \\
\hline
\end{tabular}

Table 6: Micro-hardness \& elastic moduli of plasma sprayed HA coatings

\begin{tabular}{ccc}
\hline Sample & $\begin{array}{c}\text { Micro-hardness } \\
{[\mathrm{GPa}]}\end{array}$ & $\begin{array}{c}\text { Modulus } \\
{[\mathrm{GPa}]}\end{array}$ \\
\hline $\mathrm{A}$ & 1.16 & 35.5 \\
$\mathrm{~B}$ & 0.86 & 26.8 \\
$\mathrm{C}$ & 0.06 & 12.8 \\
$\mathrm{D}$ & 0.30 & 17.3 \\
$\mathrm{E}$ & 0.26 & 18.4 \\
$\mathrm{~F}$ & 0.24 & 20.3 \\
\hline
\end{tabular}

